\title{
ORIGINAL ARTICLE Epidemiology of traumatic spinal cord injuries in Iceland from 1975 to 2009
}

\author{
S Knútsdóttir ${ }^{1}, \mathrm{H}$ Thórisdóttir ${ }^{1}, \mathrm{~K}$ Sigvaldason ${ }^{2}, \mathrm{H}$ Jónsson $\mathrm{Jr}^{3,4}, \mathrm{~A}$ Björnsson ${ }^{5}$ and $\mathrm{P}$ Ingvarsson $^{1}$
}

Study design: Retrospective population-based epidemiological study.

Objectives: To assess the nationwide, population-based incidence, causes, age, gender, extent and prevalence of spinal cord injuries (SCIs) in Iceland from 1975 to 2009.

Setting: Landspitali University Hospital in Iceland, the single referral center for SCIs in Iceland.

Methods: A retrospective review of hospital records on all admissions due to SCls. Analysis of incidence, causes, age, gender, extent of injury and prevalence.

Results: A total of 207 patients with traumatic spinal cord injury (TSCI) were admitted: males $72 \%$, females $28 \%$. The percentage of females with TSCl increased to 37\% in 2000-2004. Mean age at injury was 38 years. Average incidence per million population per year was 30 in 1975-1979, 12.5 in 1995-1999 and 33.5 in 2005-2009. Thirty-day mortality was 6.3\%. Causes of injury were road traffic accidents (RTA) in $42.5 \%$ of the cases; the majority did not use seatbelts. Falls amounted to $30.9 \%$, with an increase of low falls among the elderly causing incomplete cervical lesions. Sport/leisure activities were the cause in $18.8 \%$, of which $54 \%$ occurred after 2000. The main single cause of TSCI in sport/leisure were horse-riding accidents, followed by winter sport accidents, especially among women. Other causes constituted $7.7 \%$. The injury was complete in $39 \%$; cervical lesions were $57 \%$ and thoracic/lumbar lesions were 43\%. In December 2009, the crude prevalence rate was 526 per million population.

Conclusions: The findings showed a significant increase of TSCI in 2005-2009, especially in sport/leisure accidents and incomplete cervical lesions due to falls among elderly. Prevention strategies need to focus on these risk groups and on seatbelt use.

Spinal Cord (2012) 50, 123-126; doi:10.1038/sc.2011.105; published online 27 September 2011

Keywords: traumatic spinal cord injury; incidence; prevalence; cause; gender; age

\section{INTRODUCTION}

Spinal cord injury (SCI) has a lifelong serious impact and has high economic costs for the injured patients, their families as well as for the society. Even though research is progressing, curative treatment for this serious injury is still not available. Therefore, it is essential to develop programs for prevention of SCIs. ${ }^{1}$

In a literature survey on the incidence, prevalence and epidemiology of traumatic spinal cord injury (TSCI) in 2006, Wyndaele and Wyndaele $^{2}$ found large differences in the incidence of TSCI worldwide. According to their findings, the incidence varied between 10.4 and 83 per million population, whereas most countries reported an incidence of 15-30 per million population. However, the studies had different inclusion criteria. Some of them reported the incidence in those who survived the acute stage $e^{3}$ whereas other studies included pre-hospital mortality cases as well. ${ }^{4}$ Epidemiological studies from Canada ${ }^{5}$ included patients from 15 years of age, and studies from Sweden ${ }^{6}$ and Finland ${ }^{7}$ included patients from 16 years of age, whereas a study from Western Norway ${ }^{8}$ included all ages. Direct comparison between studies can therefore be difficult because of the different inclusion criteria and differences in data collection. Epidemiological studies can be hospital based or population based, where national incidence and prevalence is often estimated from a smaller portion of the population.
Case verification and quality of registers must also be reliable so that all cases of TSCI are recorded.

The population of Iceland increased from 217000 to 320000 inhabitants during the study period. ${ }^{9}$ Landspitali University Hospital is the only referral hospital for TSCI in Iceland and the Department of Rehabilitation the only center in Iceland with a multidisciplinary SCI team. The fact that all TSCI patients in Iceland have been admitted to Landspitali University Hospital in Reykjavík for more than three decades gives a good ground for a nationwide population-based study of the epidemiology of TSCI. The aim of this study was to collect information and analyze changes in the incidence, causes, age, gender and extent of all TSCI cases in Iceland from 1975 to 2009 and to estimate the prevalence of TSCI.

Analyzing the risk groups for TSCI is important in order to be able to improve prevention strategies, management and health-care services for TSCI.

\section{MATERIALS AND METHODS}

In a descriptive retrospective study, hospital records from Landspitali University Hospital were screened for TSCI patients with the ICD-9 (International Statistical Classification of diseases and related health problems) diagnostic codes 806 and $952,{ }^{10}$ and since 1997 with the ICD-10 diagnostic codes S14, S24

\footnotetext{
${ }^{1}$ Rehabilitation Department, Landspitali University Hospital, Reykjavík, Iceland; ${ }^{2}$ Anaesthesia Department, Intensive Care Unit, Landspitali University Hospital, Reykjavík, Iceland; ${ }^{3}$ Orthopaedic Department, Landspitali University Hospital, Reykjavík, Iceland; ${ }^{4}$ Institute of Orthopaedic Sciences, University of Iceland, Reykjavík, Iceland and ${ }^{5}$ Neurosurgical Department, Landspitali University Hospital, Reykjavík, Iceland

Correspondence: S Knútsdóttir, Rehabilitation Department, Landspitali University Hospital, Reykjavík 108, Iceland.

E-mail: sigrunkn@landspitali.is
}

Received 17 February 2011; revised and accepted 16 August 2011; published online 27 September 2011 
and S34. ${ }^{11}$ Patients with isolated injuries of nerve roots and patients diagnosed with a symptom duration of $<2$ weeks were excluded from this study.

TSCI-related injuries causing death before reaching hospital were also excluded. Statistics on the Icelandic population during the period were acquired from the Statistics Iceland. ${ }^{9}$ The study was approved by the Hospital Ethics Committee and the Data Protection Authority in Iceland.

\section{Definition and classifications}

The causes of injury were defined according to the International SCI core data set. ${ }^{12}$ RTA were subdivided into car, motorcycle, bicycle and pedestrian accidents. Falls were subdivided into low falls $(<1 \mathrm{~m})$, high falls $(1-5 \mathrm{~m})$ and high-energy injuries $(>5 \mathrm{~m})$. Sport/leisure-related accidents were subdivided into horse-riding accidents, winter sport accidents such as skiing, snowboards and snow scooter accidents, diving accidents and other sport/ leisure-related accidents, which included paragliding, bicycling, four-wheel terrain vehicles, motorcycling, gymnastics and parachuting. Other causes of injury included blows, airplane accidents and assaults. The level and extent of SCI was defined according to the International Neurological Classification of Spinal Injury using the American Spinal Injury Association Impairment scale at discharge from the hospital, including American Spinal Injury Association A to American Spinal Injury Association E classification. ${ }^{13}$ The mortality rate was defined as death within 30 days of injury.

\section{Statistical analysis}

The study was a descriptive analysis of all TSCI cases in Iceland during the study period. The crude annual incidence of TSCI in Iceland was computed for each 5-year interval from 1975 to 2009. The number of cases each year is assumed to follow a Poisson distribution. Accordingly, 95\% confidence interval was calculated for the number of cases per million population. The prevalence for 2009 was calculated including patients from 1973 to 1974 who were alive on 31 December 2009. The Pearson $\chi^{2}$-test was used to compare proportions and to test associations between variables. The level of significance was set at 0.05 .

\section{RESULTS}

\section{Incidence}

A total of 207 TSCI patients were admitted to the hospital during the study period and $86 \%$ of them ( $N: 179)$ were admitted to the Rehabilitation Department following the acute stage. The crude annual incidence per million population per year was 30 in 19751979, which decreased to 12.5 in 1995-1999 and increased to 33.5 in 2005-2009. The increase in 2005-2009 compared with 1975-2004 was significant $(P=0.002)$ (Table 1$)$.

\section{Prevalence}

The prevalence rate of TSCI was based on the survival data on 31 December 2009 of all SCI patients included in the study, as well as of 10 patients injured in 1973 and 1974. A total of 167 TSCI patients were alive, giving a crude prevalence rate of 526 per million population.

Table $1 \mathrm{TSCl}$ in Iceland 1975-2009: number of cases and crude annual incidence per million population in 5-year intervals

\begin{tabular}{lcccc}
\hline Years & $\begin{array}{c}\text { Number of } \\
\text { cases }\end{array}$ & $\begin{array}{c}\text { Crude annual } \\
\text { incidence per } \\
\text { million population }\end{array}$ & \multicolumn{2}{c}{$\begin{array}{c}\text { Incidence } \\
(95 \% \text { Cl) }\end{array}$} \\
\hline $1975-1979$ & 33 & 30 & 20.5 & 41.8 \\
$1980-1984$ & 21 & 18 & 11 & 27.4 \\
$1985-1989$ & 28 & 23 & 15 & 32.8 \\
$1990-1994$ & 26 & 20 & 13 & 29 \\
$1995-1999$ & 17 & 12.5 & 7.3 & 20 \\
$2000-2004$ & 30 & 21 & 14 & 29.8 \\
$2005-2009$ & 52 & 33.5 & 25 & 44 \\
Total & 207 & & & \\
\hline
\end{tabular}

\section{Gender and age}

Males were $72 \%$ ( $N: 150)$ and females $28 \%$ ( $N: 57)$. In 2000-2004, the female ratio increased to $37 \%$. Fifty-one percent of all the females $(N$ : 29) were injured after $2000,19 \%(N: 11)$ in $2000-2004$ and $32 \%(N$ : 18 ) in 2005-2009 (Figure 1).

Mean age at injury was 38 years ( $4-83$ years), similar for males and females. Patients aged $\leq 30$ were $43 \%$ ( $N$ : 90). Patients older than 61 years were $14 \%$ ( $N: 29)$, with a statistically significant increase in the period 2005-2009, as 38\% of them were injured during that period $(P=0.006)$.

\section{Causes of injury}

RTA was the most common single cause of injury, resulting in $42.5 \%$ $(N: 88)$ of TSCI patients. The majority were males $(68 \%, N: 60)$ and the mean age was 33.7 years, 34.6/30.3 years for males/females, respectively.

In $91 \%(N: 80)$ of RTA, the injured patients were involved in car accidents, of whom 5 were pedestrians. Motorcycle accidents were the cause of TSCI in seven cases and one was due to a bicycle accident. The majority of car accidents occurred in rural areas, where the driver lost control of the car, resulting in a rollover. In $72 \%(N: 54)$ of TSCI patients from 75 car accidents it was recorded that seatbelts were not used. Information on seatbelt usage was not available in 5\% of the patient records ( $N: 4)$. Falls were the cause of injury in $30.9 \%$ of the cases $(N: 64)$, with a male/female ratio of $49 / 15$. The mean age in the group of low falls $(<1 \mathrm{~m})$ was 62.5 years, while the high falls occurred mainly in the younger age groups. The mean age was 43 years for high falls $(1-5 \mathrm{~m})$ and 31.4 years for high-energy falls $(>5 \mathrm{~m}$ ) (Table 2).

There was a significant increase in falls in 2005-2009 compared with previous years, as $33 \%$ of all falls $(N: 21)$ occurred in this period $(P=0.001)$. Falls were the cause of injury in $55 \%(N: 16)$ of the 29 patients who were $\geq 61$, with a male/female ratio of $10 / 6$. Eight of the falls in this age group occurred in 2005-2009. Work-related falls were 23.4\% (N: 15) of all falls, of which 6 occurred in 2005-2009. The majority of the work-related falls leading to TSCI occurred in the construction industry.

Sport/leisure activities were the cause of TSCI in 19\% of the cases $(N: 39)$, males were $67 \%(N: 26)$. Fifty-four percent $(N: 21)$ of all TSCI due to sport/leisure activities occurred after 2000; $23 \%$ (N: 9) in 20002004 and $31 \%(N: 12)$ in 2005-2009, which was a significant increase $(P=0.02)$. The main single cause of TSCI in sport/leisure activities were horse-riding accidents $(N: 14)$, that is, $36 \%$ of all sport/leisure accidents, with a male/female ratio of $7 / 7$. Winter sports, such as skiing, snowboards and snow-scooter accidents, were the cause of injury in $23 \%(N: 9)$ of sport/leisure accidents, with a male/female ratio of $4 / 5$.

Other causes of sport/leisure accidents leading to TSCI were diving $(N: 5)$, paragliding $(N: 3)$, gymnastics $(N: 2)$, bicycling $(N: 2)$,

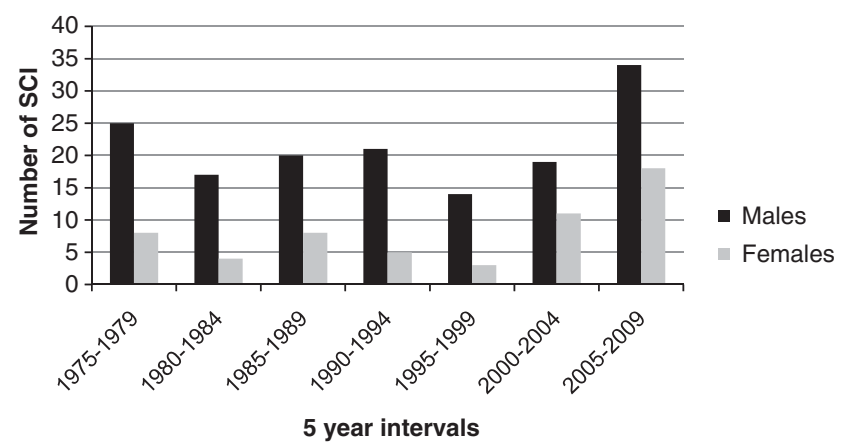

Figure 1 Gender of TSCI in 5-year intervals ( $N: 207$ ). 
Table 2 Height of falls related to age groups

\begin{tabular}{lllccc}
\hline $\begin{array}{l}\text { Height of } \\
\text { fall }(m)\end{array}$ & No. (\%) & Mean age & $5-30$ years & 31-60 years & $>60$ years \\
\hline$<1$ & $20(31 \%)$ & 62.5 & 1 & 8 & 11 \\
$1-5$ & $26(41 \%)$ & 43 & 9 & 12 & 5 \\
$>5$ & $18(28 \%)$ & 31.4 & 11 & 7 & 0 \\
Total (\%) & $64(100 \%)$ & 45.9 & $21(33 \%)$ & $27(42 \%)$ & $16(25 \%)$ \\
\hline
\end{tabular}

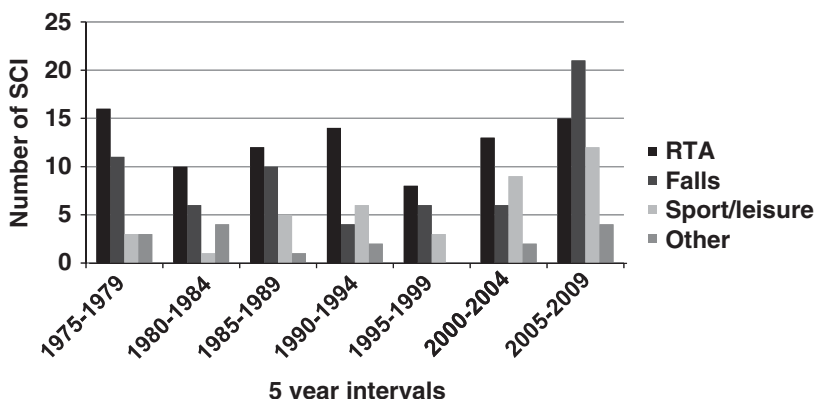

Figure 2 Causes of TSCl in 5-year intervals ( $N: 207$ ).

four-wheel terrain vehicle accidents $(N: 2)$, motorcycling $(N: 1)$ and parachuting $(N: 1)$. Eight percent $(N: 16)$ of all TSCI cases were due to other causes, including blows $(N: 10)$, airplane accidents $(N: 3)$ and assaults (N: 3) (Figure 2).

\section{Level and extent of injury}

According to the American Spinal Injury Association impairment scale, the injury was complete in $39 \%$ of the cases $(N: 81)$. Cervical lesions were $57 \%(N: 118)$, of which $38 \%(N: 45)$ were complete and $62 \%$ ( $N: 73)$ were incomplete lesions. Thoracic/lumbar lesions were $43 \%$ ( $N: 89$ ), of which $40 \%$ ( $N: 36)$ were complete and $60 \%$ ( $N: 53$ ) were incomplete lesions. There was a considerable increase in incomplete cervical lesions after 2000 as $17 \%(N: 12)$ of these lesions occurred in 2000-2004 and 22\% (N: 16) in 2005-2009. Thirty-three percent ( $N: 12)$ of complete thoracic/lumbar lesions and $30 \%(N: 16)$ of incomplete thoracic/lumbar lesions occurred in 2005-2009.

The 30 -day mortality rate was $6.3 \%$ ( $N: 13$ ). Of these 12 patients had a complete cervical lesion and 1 had an incomplete cervical lesion. A total of 11 patients died within 5 days of injury.

The age groups and cause of injury related to the level and extent of injury are shown in Table 3.

\section{DISCUSSION}

According to our nationwide study, the incidence of TSCI in Iceland decreased in 1995-1999 and increased significantly in 2005-2009 compared with 1975-2004. The incidence of SCI varies considerably around the world. Studies from other countries show an incidence rate of 19.6 per million population in the Stockholm region in Sweden, ${ }^{6} 10$ per million population in Finland ${ }^{7}$ and 26.3 per million population in Western Norway. ${ }^{8}$ The increase in incidence rate in our study was higher than that seen in these studies, but lower than that in studies from Canada ${ }^{5}$ and the United States ${ }^{14}$. Direct comparison is however difficult, as the inclusion criteria in the studies from Canada, Sweden and Finland are different.

There was a considerable increase in female ratio in 2000-2004/ 2005-2009, which is in contrast with a similar study from Western
Table 3 Age groups, level and extent of $\mathrm{TSCl}$ related to causes of injury

\begin{tabular}{|c|c|c|c|c|c|c|}
\hline & \multirow[t]{2}{*}{$\mathrm{N}$} & \multirow[t]{2}{*}{$\%$} & \multicolumn{2}{|c|}{ Tetraplegia } & \multicolumn{2}{|c|}{ Paraplegia } \\
\hline & & & Complete & Incomplete & Complete & Incomplete \\
\hline RTA (years) & 88 & 43 & & & & \\
\hline $4-30$ & 45 & 23 & 13 & 10 & 10 & 12 \\
\hline $31-60$ & 35 & 17 & 8 & 15 & 8 & 4 \\
\hline Over 60 & 8 & 5 & 4 & 4 & & \\
\hline Falls (years) & 64 & 31 & & & & \\
\hline $4-30$ & 21 & 10 & 3 & 2 & 5 & 11 \\
\hline $31-60$ & 27 & 14 & 3 & 12 & 3 & 9 \\
\hline Over 60 & 16 & 7 & 4 & 10 & & 2 \\
\hline Sport/leisure (years) & 39 & 19 & & & & \\
\hline $4-30$ & 17 & 9 & 3 & 5 & 5 & 4 \\
\hline $31-60$ & 18 & 9 & 4 & 7 & 2 & 5 \\
\hline Over 60 & 4 & 2 & & 3 & 1 & \\
\hline Other (years) & 16 & 8 & & & & \\
\hline $4-30$ & 8 & 4 & 2 & 2 & 2 & 2 \\
\hline $31-60$ & 7 & 2 & & 3 & & 4 \\
\hline Over 60 & 1 & & 1 & & & \\
\hline Total $N$ & 207 & & 45 & 73 & 36 & 53 \\
\hline Total \% & & & 21.7 & 35.3 & 17.4 & 25.6 \\
\hline
\end{tabular}

Abbreviation: RTA, road traffic accidents.

Norway, ${ }^{8}$ where the incidence rate for the males increased more than for females. However, some other studies have shown a slight increase in the female ratio. ${ }^{2,14}$

RTA were the leading cause of injury, which is also seen in studies from Canada ${ }^{5}$ and the United States. ${ }^{14}$ The majority of TSCI from RTA were seen in the younger age groups, as reported also by other studies. ${ }^{1,8,14,15}$ The quality of roads in Iceland has improved considerably during the past decades and the number of cars has increased enormously during these 35 years. RTA have not increased in proportion to the population growth and the increased car ownership. The fact that the majority of RTA that resulted in TSCI occurred in rural areas where seatbelts were not used is a matter of great concern.

Falls were the second leading cause of TSCI, whereas findings from the Nordic countries showed that falls are the leading cause of injury. ${ }^{6-8}$ The study showed a significant increase in falls during 2005-2009. Falls were the predominant cause of injury in the age group $\geq 61$, most often low falls leading to incomplete cervical lesion. Similar results have been shown in other studies. ${ }^{1,5,7,8,14-17}$ The majority of work-related falls leading to TSCI occurred in the construction industry. In recent years, the prevention strategies in the construction industry have improved considerably with increased safety regulations. In 2005-2009 an increase in the workforce in the construction industry in Iceland was seen, and this might explain the increased work-related TSCI due to falls during that period.

There was a significant increase in sport/leisure-related accidents in 2000-2004/2005-2009. Horse riding and winter sports were the main causes of sport and leisure accidents, especially among women, and is of concern. In recent years, horse riding has become very popular in Iceland.

The incidence of cervical injures was higher than that of thoracic/ lumbar injuries as in many other studies. ${ }^{1,3,5,6,8,14-16}$ In one-third of 
the patients, the SCI was complete. There was an increase in complete and incomplete thoracic/lumbar lesions and incomplete cervical lesions after 2000, especially in 2005-2009.

The prevalence rate of TSCI in this study was higher than that reported in a study from Finland, where the prevalence rate was 289 per million population ${ }^{18}$ and in a study from Western Norway, ${ }^{8}$ where the prevalence rate was 365 per million population. Studies on prevalence of TSCI have shown 534 per million population among persons of all ages in Australia, ${ }^{19}$ which is similar to our findings, and 700-755 per million population in the United States, according to Wyndaele in $2006^{2}$

The authors have considered the reason for the decrease in incidence of TSCI in 1995-1999 and the increase of TSCI in 20052009. These changes in incidence coincide with changes in the gross domestic product and private consumption in Iceland in these periods, as there was an economic downswing in Iceland in the period 1990-1999 and an economic upswing after 2000 according to an overview of Gross Domestic Products and Gross National Product 1945-2010 from the Statistics Iceland. ${ }^{20}$ This might have led to changes in lifestyle and increased participation in sport/leisure activities leading to an increase in SCIs.

The study included the total population-based nationwide number of patients with TSCI over a period of more than three decades, with a good demographic overview of patients, causes, level and extent of injury, trends and incidence.

The main findings of our study showed a decrease in incidence in 1995-1999 and an increase of TSCI in 2005-2009, especially increased sport/leisure accidents and incomplete cervical lesions due to falls among the elderly, and this is of concern. Although seatbelt use is mandatory in Iceland, the number of RTAs where seat belts were not used is also of great concern.

On the basis of these findings on the epidemiology of TSCI in Iceland and the increase of TSCI, prevention strategies need to be improved with special emphasis on sport and leisure activities and with a focus on horse-riding accidents and winter sport, especially among women. It is also of great importance to put a special emphasis on prevention against falls, especially among the elderly. Improved prevention strategies related to seat belt use and driving in rural areas is also needed.

\section{CONFLICT OF INTEREST}

The authors declare no conflict of interest.

\section{ACKNOWLEDGEMENTS}

We thank the Research Fund of Landspitali University Hospital for their financial support and also Ingibjörg Richter for data collection.

1 Ackery A, Tator C, Krassioukov A. A global perspective on spinal cord injury epidemiology. J Neurotrauma 2004; 21: 1355-1370.

2 Wyndaele M, Wyndaele JJ. Incidence, prevalence and epidemiology of spinal cord injury: what learns a worldwide literature survey? Spinal Cord 2006; 44: 523-529.

3 van Asbeck FWA, Post MWM, Pangalila RF. An epidemiological description of spinal cord injuries in the Netherlands in 1994. Spinal Cord 2000; 38: 420-424.

4 Martins F, Freitas F, Martins L, Dartigues JF, Barat M. Spinal cord injuries epidemiology in Portugal's central region. Spinal Cord 1998; 36: 574-576.

5 Pickett GE, Campos-Benitez M, Keller JL, Duggal N. Epidemiology of traumatic spinal cord injury in Canada. Spine 2006; 31: 799-805.

6 Divangoglou A, Levi R. Incidence of traumatic spinal cord injury in Thessaloniki, Greece and Stockholm, Sweden: a prospective population-based study. Spinal Cord 2009; 47: 796-801.

7 Ahoniemi E, ALaranta H, Hokkinen EM, Valtonen K, Kautiainen $\mathrm{H}$. Incidence of traumatic spinal cord injuries in Finland over a 30-year period. Spinal Cord 2008; 46: 781-784.

8 Hagen EM, Eide GE, Rekand T, Gilhus NE, Gronning M. A 50-year follow-up of the incidence of traumatic spinal cord injuries in West Norway. Spinal Cord 2010; 48 : 313-318.

9 Statistics Iceland, Borgartun 21a,150 Reykjavík, Iceland. Population overview - key figures 1703-2011. Latest update: 8 February 2011. Reference time: 17032011. http://www.statice.is/Statistics/Population/ Overview.

10 The Manual of the International Statistical Classification of Diseases, Injuries and Causes of Death (ICD 9), Ninth Revision. World Health Organization: Geneva 1977.

11 International Statistical Classification of Diseases and Related Health Problems (ICD 10), Tenth Revision. World Health Organization: Geneva 1992.

12 Biering-Sörensen F, Charlifue S, DeVivo M, Noonan V, Post M, Stripling R et al. International spinal cord injury data sets. Spinal Cord 2006; 44: 530-534.

13 Maynard Jr FM, Bracken MB, Creasy G, Ditunno Jr JF, Donowan WH, Ducker Tb et al. International standards for neurological and functional classification of spinal cord injury. Spinal Cord 1997; 35: 266-274.

14 Jackson AB, Dijkers M, Devivo MJ, Poczattek RB. A demographic profile of new traumatic spinal cord injuries: change and stability over 30 years. Arch Phys Med Rehabil 2004; 85: 1740-1748.

15 Krassioukov AV, Furlan JC, Fehlings MC. Medical co-morbidities, secondary complications, and mortality in elderly with acute spinal cord injury. J Neurotrauma 2003; 20: 391-399.

16 Jabbour P, Fehlings M, Vaccaro AR, Harrop JS. Traumatic spine injuries in the geriatric population. Neurosurg Focus 2008; 25: E16.

17 O'Connor PJ. Forecasting of spinal cord injury annual case numbers in Australia. Arch Phys Med Rehabil 2005; 86: 48-51.

18 Dahlberg A, Kotila M, Läppanen $\mathrm{P}$, Kautianen $\mathrm{H}$, Alaranta $\mathrm{H}$. Prevalence of spinal cord injury in Helsinki. Spinal Cord 2005; 43: 47-50.

19 O'Connor PJ. Prevalence of spinal cord injury in Australia. Spinal Cord 2005; 43 : 42-46.

20 Statistics Iceland, Borgartun 21a,150 Reykjavík, Iceland. Overview of Gross Domestic Products and Gross National Product 1945-2010, Latest update: 8 March 2011. Reference time: 1945-2010. (http://www.statice.is/Statistics/National-accounts-andpublic-fin/National-overview) 